Jurnal Inkofar * Volume 1 No. 2 Desember 2019 * ISSN: 2615-3645 (Print) / 2581-2920 (Online)

Tersedia secara online di: http://www.politeknikmeta.ac.id/meta/ojs/

\title{
APLIKASI E-KATALOG YUDISIUM BUKTI PENGAMBILAN IJAZAH DAN TRANSKRIP NILAI
}

\author{
Rina Firliana ${ }^{1}$, Rini Indriati ${ }^{2}$, Intan Nur Farida ${ }^{3,}$, Ratih Kumalasari Niswatin ${ }^{4}$ \\ ${ }^{1}$ Sistem Informasi / Fakultas Teknik / Universitas Nusantara PGRI /rinafirliana77@gmail.com \\ ${ }^{2}$ Sistem Informasi / Fakultas Teknik / Universitas Nusantara PGRI / rini.indriati@unpkediri.ac.id \\ ${ }^{3}$ Teknik Informatika / Fakultas Teknik / Universitas Nusantara PGRI / in.nfarida@gmail.com \\ ${ }^{4}$ Teknik Informatika / Fakultas Teknik / Universitas Nusantara PGRI / ratih.workmail@gmail.com
}

\begin{abstract}
The world of work in the Student Affairs Bureau often experiences difficulties in examining diploma data and student transcript scores that have or have not been taken. The amount of data is not only tens but thousands so that it is difficult to check. Because the student bureau really needs a computer media that can archive thousands of student data. Especially those needed to record or store diploma data and transcripts that have been taken. By using an integrated application and a computer media that can be used easily, safely and appropriately in the e-Catalog Application Judgment Proof of Taking Diplomas and Value Tanskrip can computerize student data and record valid evidence in taking Diplomas and Value Tanskrips. The researcher conducted the research methodology as follows: first, the researcher conducted an analysis by interviewing the relevant parties according to the diploma evidence taking system and transcripts to the Student Affairs Bureau, and subsequently did the design using Data Flow Diagrams (DFD), and program implementation using PHP. By carrying out these stages, it produces research related to taking proof of diplomas and value transcripts, where 1). Students and admins can directly input the data of graduated students for proof of diploma and transcript online. And 2). The admin can store the data so that if the student takes the system there for the diploma and transcript is declared if it has not been taken whereas if it has been taken then the system is taken so that the admin has been helped in proving that the diploma and student transcript are declared to still exist or have not been taken. So by building an application can facilitate the Student Affairs Bureau agencies in Providing information to students quickly, clearly and correctly in the process of taking a diploma and Value Transcript.
\end{abstract}

Keywords: e-catalog, diplomas, transcripts, students, student affairs bureaus

\begin{abstract}
ABSTRAK
Dunia kerja dalam Biro Kemahasiswaan sering mengalami kesulitan dalam memeriksa data ijazah dan transkrip nilai mahasiswa yang sudah atau belum diambil. Data tersebut jumlanya tidak hanya puluhan tapi ribuan sehingga kesulitan dalam pengecekkannya. Oleh karena biro kemahasiswaan sangat membutuhkan suatu media komputer yang dapat mengarsipkan ribuan data mahasiswa. Khususnya yang diperlukan untuk mencatat atau menyimpan data ijazah dan transkrip nilai yang sudah diambil. Dengan menggunakan sebuah aplikasi yang terintegrasi dan suatu media komputer yang dapat digunakan dengan mudah, aman dan tepat di Aplikasi e-KatalogYudisium Bukti Pengambilan Ijazah dan Tanskrip Nilai dapat mengoputerisasikan data-data mahasiswa serta mencatat bukti-bukti yang valid dalam pengambilan Ijazah dan Tanskrip Nilai. Peneliti melakukan metodologi penelitian sebagai berikut pertama peneliti melakukan analisa dengan wawancara dengan pihak yang bersangkutan sesuai sistem pengambilan bukti ijazah dan transkrip ke Biro Kemahasiswaan, selanjutanya melakukan perancangan dengan menggunakan Data Flow Diagram (DFD), dan implementasi program dengan menggunakan PHP. Dengan melakukan tahapantahapan tersebut maka menghasilkan penelitian yang berkaitan dengan pengambilan bukti ijasah dan transkrip nilai, dimana 1). Mahasiswa dan admin bisa langsung menginputkan data mahasiswa yudisium untuk bukti pengambilan ijasah dan transkrip secara online. Dan 2). Admin bisa menyimpan data tersebut sehingga apabila mahasiswa tersebut mengambil maka disitu sistem untuk ijazah dan transkrip dinyatakan ada apabila belum diambil sedangkan kalau sudah diambil maka sistem terambil sehingga admin sudah terbantu dalam hal membuktikan bahwa ijazah dan transkrip nilai mahasiswa dinyatakan masih ada atau belum terambil. Jadi dengan membangun suatu aplikasi tersebut dapat memudahkan instansi Biro Kemahasiswaan dalam Memberikan suatu informasi kepada mahasiswa dengan cepat, jelas dan benar dalam proses pengambilan Ijazah dan Transkrip Nilai.
\end{abstract}

Kata Kunci: e-catalog, ijazah, transkrip, mahasiswa, biro kemahasiswaan. 
Jurnal Inkofar * Volume 1 No. 2 Desember 2019 * ISSN: 2615-3645 (Print) / 2581-2920 (Online)

Tersedia secara online di: http://www.politeknikmeta.ac.id/meta/ojs/

\section{PENDAHULUAN}

Perkembangan Teknologi Informasi saat ini semakin pesat, informasi apapun dapat diperoleh dari berbagai media, baik informasi - informasi terbaru maupun sistem yang mungkin dapat diperbarui sehingga informasi harus segera di akses dengan cepat. Dalam dunia kerja, pendidikan diperlukan suatu catatan khusus guna untuk memvalidkan suatu data. Sehingga dibutuhkan suatu media yang dapat digunakan dengan mudah, aman dan tepat. Aspek dunia kerja dalam suatu Biro Kemahasiswaan membutuhkan suatu media komputer yang dapat mengarsipkan ribuan data mahasiswa. Aplikasi eKatalog Yudisium Bukti Pengambilan Ijazah dan Transkrip Nilai adalah salah satu bentuk aplikasi web yang dapat mengkomputerisasikan data-data mahasiswa yang telah lulus untuk mengambil ijasah dan transkrip nilai pada Biro Administrasi Akademik dan Kemahasiswaan. Sehingga memudahkan para staf Biro Administrasi Akademik Kemahasiswaan dalam pelayanan kemahasiswaan. Dibutuhkan suatu aplikasi modern pada Instansi Biro Administrasi Akademik dan Kemahasiswaan dalam mengarsipkan data-data mahasiswa telah lulus untuk mengambil Ijasah supaya memudahkan proses pencarian banyak data yang telah tersimpan. Berdasarkan penelitian bertujuan Aplikasi e-Katalog Yudisium Bukti Pengambilan Ijazah dan Tanskrip Nilai dapat mengoputerisasikan data-data mahasiswa serta mencatat bukti-bukti yang valid dalam pengambilan Ijazah dan Tanskrip Nilai membangun suatu aplikasi guna memudahkan instansi Biro Kemahasiswaan dalam Memberikan suatu informasi kepada mahasiswa dengan cepat, jelas dan benar dalam proses pengambilan Ijazah dan Transkrip Nilai. Penelitian ini ada dikarenakan mengacu pada penelitian-penelitian lain: 1). Ridho Pamungkas[137:2017] Perancangan sistem informasi pembayaran administrasi SMK Negeri 1 Jiwan dalam penelitian ini peneliti mencoba membangun sistem untuk mempercepat dalam pencarian dan pengelolaan data-data laporan pembayaran administrasi siswa sehingga kinerja sistem lebih efektif dan akurat. Perancangan ini menggunakan Micrososft Visual Basic 6.0. untuk memberikan pelayanan dalam pembayaran administrasi siswanya. 2). Dwi Ari Wibowo, Verry Riyanto, Syifa Nur Rakhmah [41:2017] Sistem Informasi Perpustakaan Bebasis Web Pada Smk Negeri 2 Kota Bekasi dalam penelitian ini pada umumnya perpustakaan hanya memiliki buku-buku yang disimpan di rak dari gedung atau ruang perpustakaan tetapi dalam perkembangan teknologi saat ini memanfaatkan perpustakaan dengan melakukan pengarsipan koleksi buku-buku dalam bentuk arsip digital atau yang lebih dikenal dengan e-book. Saat ini di dalam ruang lingkup pendidikan, perpustakaan digital diperlukan untuk mendukung dalam pelaksanaan pendidikan dan pengajaran, serta pengabdian dan pelayanan pada masyarakat dalam bentuk layanan yang dipermudah dengan sistem online. Perubahan paradigma dalam sistem pendidikan dan pengajaran menempatkan perpustakaan sebagai sumberdaya informasi yang sangat penting karena dimungkinkan akan memberikan kemudahan pada civitas akademika dalam aksesibilitas informasi di perpustakaan. Dalam era global seperti sekarang ini muncul berbagaiperpustakaan yang menerapkan teknologi informasi (TI) maka adapun istilah perpustakaan maya, perpustakaan elektronik, atau perpustakaan digital. 3). Indra Budi Trisno dan Wiria Candra[147:2018] Rancang Bangun Aplikasi Pencatatan Stok dan Penjualan UD Pawon Kue dalam penelitian ini peneliti kesulitan untuk menentukan laba, lama dalam mencari informasi, dan kemungkinan hilangnya catatan yang dibuat. Dan peneliti membangun aplikasi tersebut untuk memudahkan penjualan dan pencatatan dan penjualan produk-produk yang dimiliki oleh UD. 4). Manase Sahat H Simarangkir, Adam Puspabhuanasari[1:2019] Implementasi Wap (Wireless Application Protocol) Dan Web Untuk Layanan Sistem Informasi Nilai Mahasiswa Teknologi Wireless Application Protocol (WAP) merupakan penggabungan antara teknologi internet dengan teknologi nirkabel sehingga untuk mengakses informasi bisa dilakukan dimana saja selama terhubung dengan internet dan menggunakan media nirkabel. Perkembangan teknologi diberbagai bidang mendorong berkembangnya teknologi informasi dalam menghasilkan informasi yang berguna untuk pengambilan berbagai keputusan penting baik di masyarakat, institusi atau organisasi. Sistem dapat diakses oleh web admin hanya menggunakan website sedangkan untuk mengakses informasi nilai mahasiswa dapat menggunakan telepon seluler dan website. Hasil akhir penelitian yaitu menghasilkan sistem informasi, dimana mahasiswa dapat melihat nilai menggunakan telepon selular dan website. 
Jurnal Inkofar * Volume 1 No. 2 Desember 2019 * ISSN: 2615-3645 (Print) / 2581-2920 (Online)

Tersedia secara online di: http://www.politeknikmeta.ac.id/meta/ojs/

\section{STUDI PUSTAKA (JIKA DIPERLUKAN)}

2.1 E-Catalog

Pengertian sederhana e-Catalog (e-katalog) adalah suatu daftar yang dibuat secara elektronik yang bisa diakses secara online berbasis internet.

Pengertian katalog dalam KBBI (1998:396) yang dimaksud dengan katalog yaitu cari kartu, buku/buku yang memuat nama benda/informasi yang ingin diberitahukan yang disusun secara berurutan, teratur dan alfabetis.

E_Catalog adalah sistem informasi elektronik yang memuat daftar, jenis, spesifikasi teknis dan harga barang/jasa tertentu.

Keuntungan dengan adanya E-Catalog

1. Memberikan kemudahan dalam melaksanakan pengadaan untuk kebutuhan instansi.

2. Dokumen pengadaan disediakan dalam system aplikasi, sehingga mengurangi dokumens eperti dalam pengarsipan

3. Pelaksanaan E-Catalog akan terrecord, sehingga memudahkan monitoring dan memudahkan sebagai bahan analisa

4. Mempercepat penyediaan fasilitas kinerja kantor dan pelayanan masyarakat

5. Menghemat Anggaran

Melihat berbagai macam keuntungan yang diperoleh dari penggunaan E-Catalog. Sudah saatnya pemerintah Indonesia untuk mulai memperhitungkan dan memberikan porsi lebih untuk realisasi layanan semacam ini. Jika dulu masih berdalih dengan isu seputar kesiapan sumber daya manusia, untuk saat ini tentu keadaan sudah berubah.

Selalu gunakan solusi digital ini agar proses pengarsipan anda menjadi lebih cepat, hemat, transparan, aman dan terpercaya.

\subsection{DFD}

Kristanto (2008:55), data flow diagram/DFD adalah suatu model logika atau proses yang dibuat untuk menggambarkan dari mana asal data dan ke mana tujuan data yang keluar dari sistem, di mana data disimpan, proses apa yang menghasilkan data tersebut dan interaksi antara data yang tersimpan dan proses yang dikenakan pada data tersebut.

\subsection{PhpMyAdmin}

- $\quad$ Menurut Arief (2011:429) PhpMyAdmin adalah "salah satu aplikasi berbasis GUI (Graphical User Interface) yang digunakan untuk mengeolal database MySQL".

- $\quad$ Menurut MADCOMS (2016: 186) "PhpMyAdmin adalah sebuah aplikasi Open Source yang berfungsi untuk memudahkan manajemen MySQL. Dengan menggunakan PhpMyAdmin, dapat membuat database, membuat tabel, meng-insert, menhapus dan meng-update data dengan GUI dan terasa lebih mudah, tanpa perlu mengetikkan perintah SQL secara manual".

- $\quad$ Menurut Nugroho (2013:71), phpMyAdmin adalah tools yang dapat digunakan dengan mudah untuk memanajemen database MySQL secara visual dan Server MySQ1, sehingga kita tidak perlu lagi harus menulis query SQL setiap akan melakukan perintah operasi database". Tools ini cukup populer, Anda dapat mendapatkan fasilitas ini ketika menginstal paket triad phpMyAdmin, karena termasuk dalam xampp yang sudah di instal.

- Menurut Buana (2014:2) , phpMyAdmin adalah salah satu aplikasi yang digunakan untuk memudahkan dalam melakukan pengelolaan database MySQL. phpMyAdmin merupakan aplikasi web yang bersifat opensource.

- $\quad$ Menurut Muhammad Sadeli (2014:10)' PhpMyadmin adalah sebuah software yang berbentuk seperti halaman situs yang terdapat pada web server. Fungsi dari halaman ini adalah, sebagai pengendali database MySQL. Karena dengan adanya halaman ini semua hal tersebut dapat dilakukan hanya dengan meng-klik menu fungsi yang ada pada halaman PhpMyadmin.

\subsection{MySql}

Kadir (2013:412), "MySQL adalah nama sebuah database server yang menangani akses database yang selalu dalam bentuk pernyataan SQL (Structured Query Language) yaitu suatu bahasa yang digunakan untuk mengakses database relasional". Anhar (2010:21), "MySQL (My Structure Query Language) adalah sebuah perangkat lunak sistem manajemen basis data SQL (Database Management System) atau DBMS dari sekian banyak DBMS, seperti Oracle, MS SQL, Postagre SQL, dan lainlain". 


\section{HASIL, ANALISA DATA DAN PEMBAHASAN}

Metode yang digunakan untuk pengembangan sistem yang akan dibuat adalah metode waterfall. Metode waterfall adalah sebuah metode pengembangan sistem atau software yang bersifat sekuensial linier yaitu proses pengerjaan dari suatu sistem dilakukan secara berurutan dan sistematis. Berikut ini merupakan tahapan - tahapan dari metode waterfall.

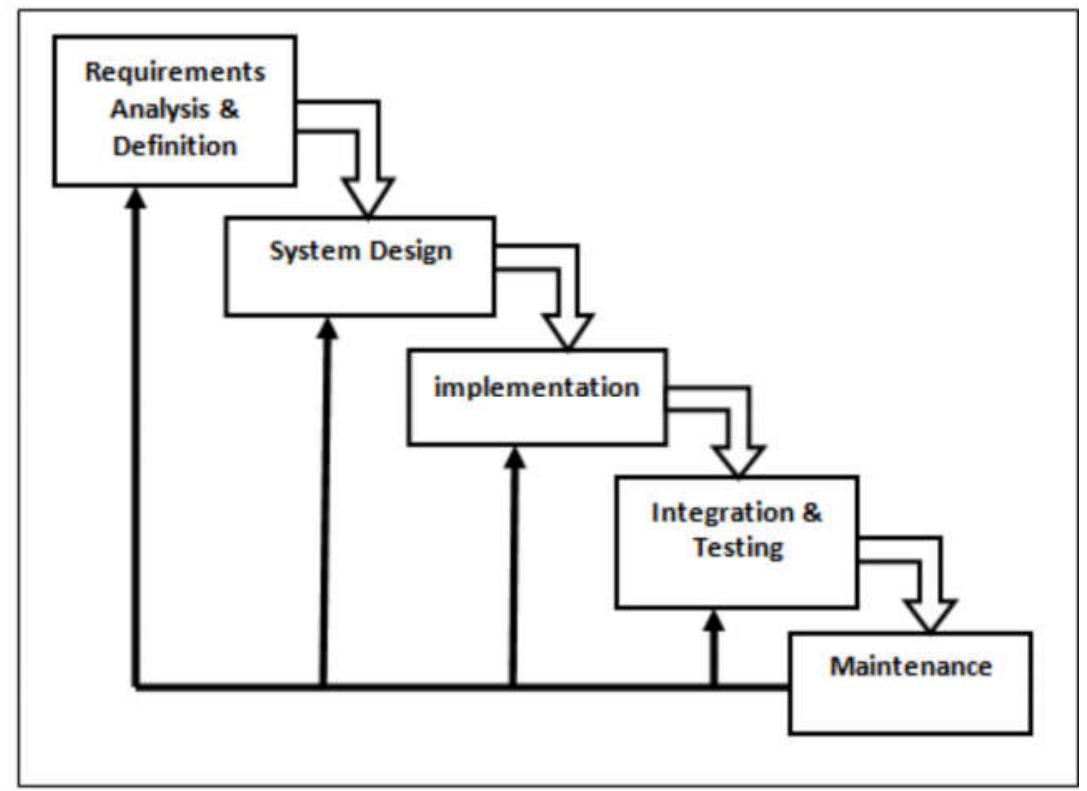

Gambar 1. Tahapan Dalam Model Waterfall Menurut Sommervile

Secara garis besar metode waterfall mempunyai tahapan sebagai berikut ini :

1) Analisa dan Definisi Kebutuhan (Requirement Analysis \& Definition)

Pada tahap ini dilakukan analisa terhadap kebutuhan sistem baik software dan hardware. Dalam tahap ini juga dilakukan proses pengumpulan data dengan cara melakukan studi literatur, wawancara, observasi dan dokumentasi mengenai data - data ijazah dan transkrip mahasiswa yang diperlukan. Tahapan ini akan menghasilkan dokumen user requirement atau data yang berhubungan dengan keinginan user dalam pembuatan sistem. Dokumen ini yang akan menjadi acuan dalam tahap desain sistem.

2) Desain Sistem (System Design)

Tahap desain sistem akan menerjemahkan syarat kebutuhan ke sebuah perancangan perangkat lunak sebelum dibuat coding. Pada proses ini dibuat perancangan arsitektur perangkat lunak, struktur data, representasi interface, dan algoritma prosedural.

3) Pembuatan Sistem (Implementation)

Pada tahap ini dilakukan penerjemahan dari proses desain kedalam bahasa yang bisa dikenali oleh komputer. Dalam proses ini dilakukan pembuatan program (coding) sesuai dengan sistem. Bahasa pemrograman yang digunakan dalam sistem ini adalah PHP, database yang digunakan untuk menyimpan data adalah MySQL.

4) Integrasi dan Pengujian Sistem(Integration \& Testing)

Pada tahap ini dilakukan pengujian terhadap program yang telah dibuat dengan cara melakukan uji coba terhadap semua fungsi dan modul pada sistem.

5) Pemeliharaan (Maintenance)

Sistem yang telah dibuat dapat mengalami perubahan yang disebabkan kebutuhan perkembangan fungsional dari user atau disebabkan penyesuaian terhadap perkembangan lingkungan seperti harware, software, peripheral, atau sistem operasi baru. 


\subsection{Rancangan Sistem}

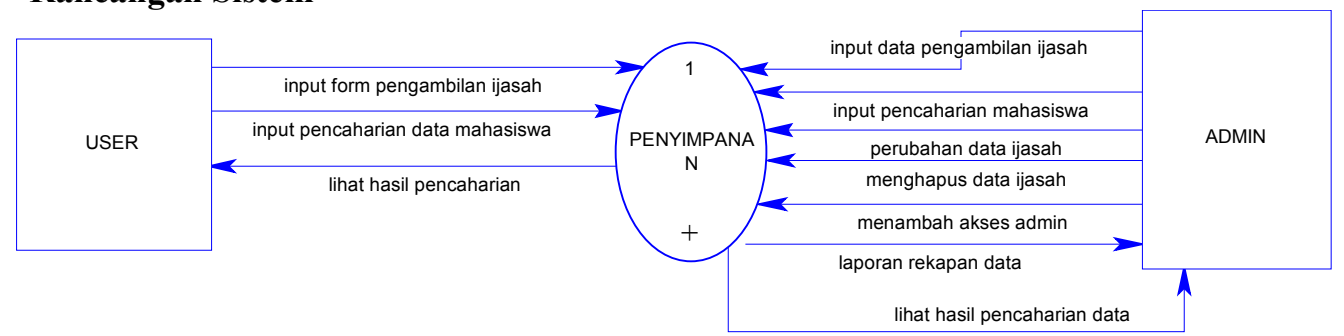

Gambar 2. Kontek Diagram Sistem E-Katalog

Pada konteks diagram system e-KatalogYudisiumBuktiPengambilanIjazah dan TranskripNilaidimulai dari entityUser yang memilikibeberapaakses yang terdiridari input form pengambilan ijazah, input pencarian data mahasiswa, melihat hasil pencarian. Kemudian entity Admin yang memiliki beberapa akses yaitu input data pengambilan ijazah, input pencarian data mahasiswa, merubah data ijazah, menghapus data ijazah, menambah akses admin, melihat laporan rekapan data, melihat hasil pencarian data.

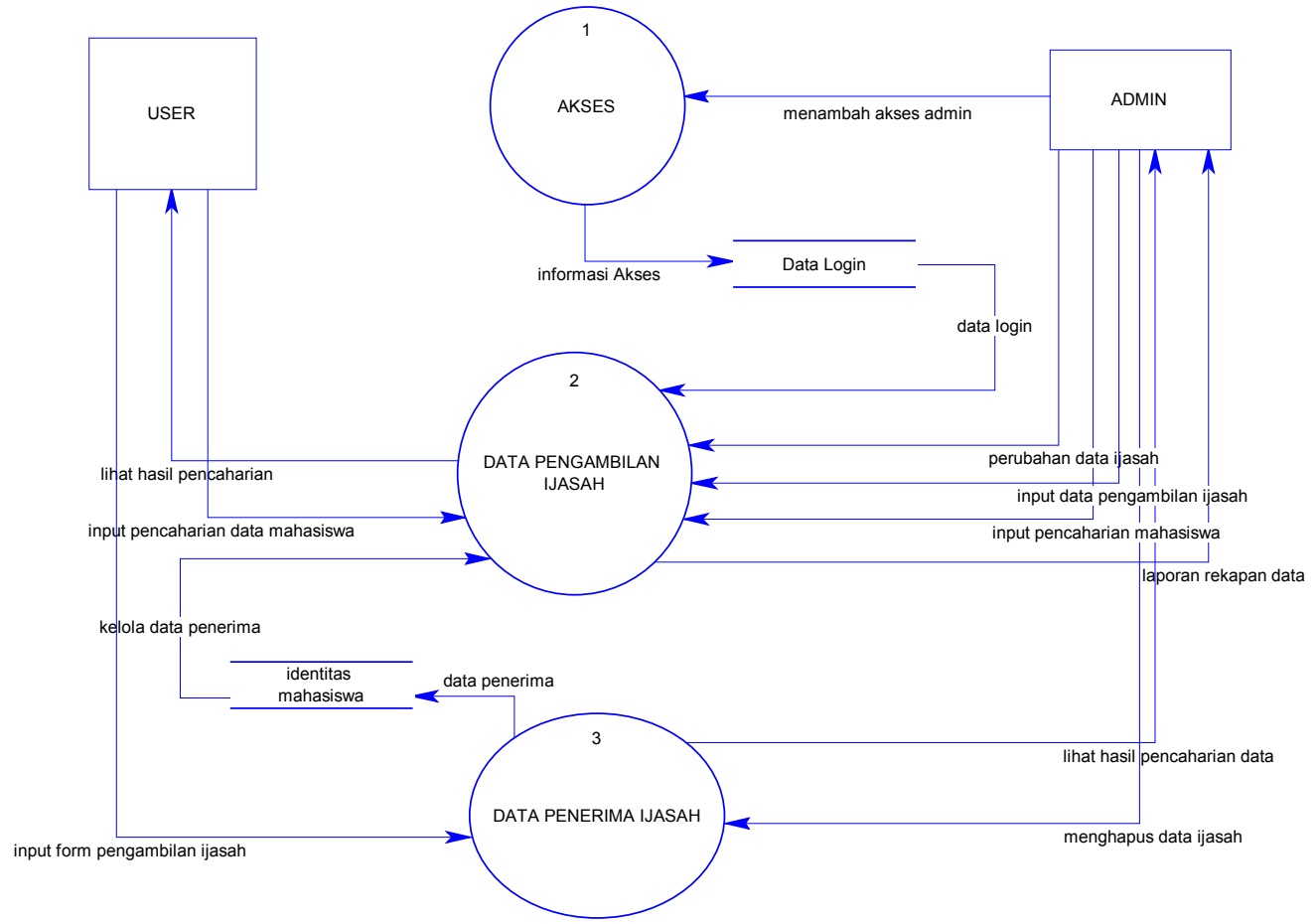

Gambar 3. Data Flow Diagram Sistem E-Katalog

Dari sistem DFD diatas ada 3 proses yaitu akses, proses data pengambilan ijasah dan proses data penerima ijasah. Pertamaproses aksesadmin melakukan akses login, kedua proses data pengambilan ijasah melakukan proses input data pengambilan ijasah pencarian data, perubahan data ijasah dan melaporkan rekap data. Sedangkan untuk user untuk proses data pengambilan ijasah, user melakukan input pencarian data mahasiswa dan lihat hasil pencarian. Proses ke tiga proses penerima ijasah adminlihat hasil pencarian data dan menghapus data sedangkan user input form pengajuan ijasah.

\subsection{Analisa Sistem}

Analisa Sistem dapat dijelaskan dari beberapa seperti kegunaan sistem, alur dari system kemudian penggambaran desain antarmuka yang terdapat berbagai konten-konten menu pada aplikasi tersebut. Kegunaan sistem mempermudah dalam mendata mahasiswa yang telah mengambil ijazah dan transkrip nilai, menyingkat waktu dalam proses pengambilan ijazah dantranskrip nilai.Memudahkan instansi Biro Administrasi Akademik dan Kemahasiswaan dalam mengarsipkan data-data mahasiswa telah lulus untuk mengambil ijasah dan transkrip nilai. 
Pada penjelasan pada alur sistem, penulis menggambarkan alur proses pengambilan ijazah dan transkrip nilai dalam bentuk kontekalur sederhana sebagai berikut:

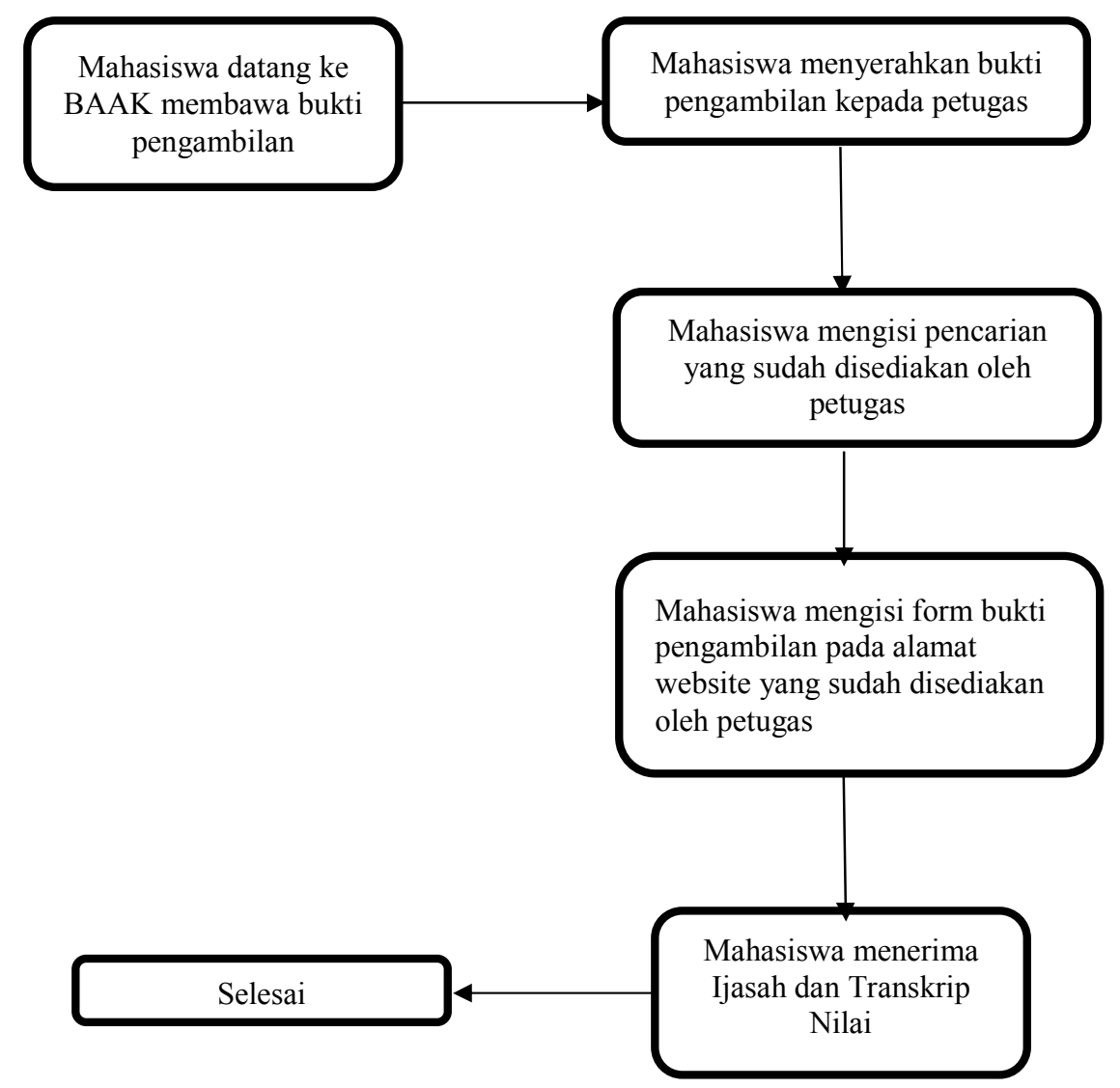

Gambar 4. Alur Sistem Pengambilan Ijazah

\subsection{Hasil}

\subsubsection{Form Interface dan Input Pencarian User}

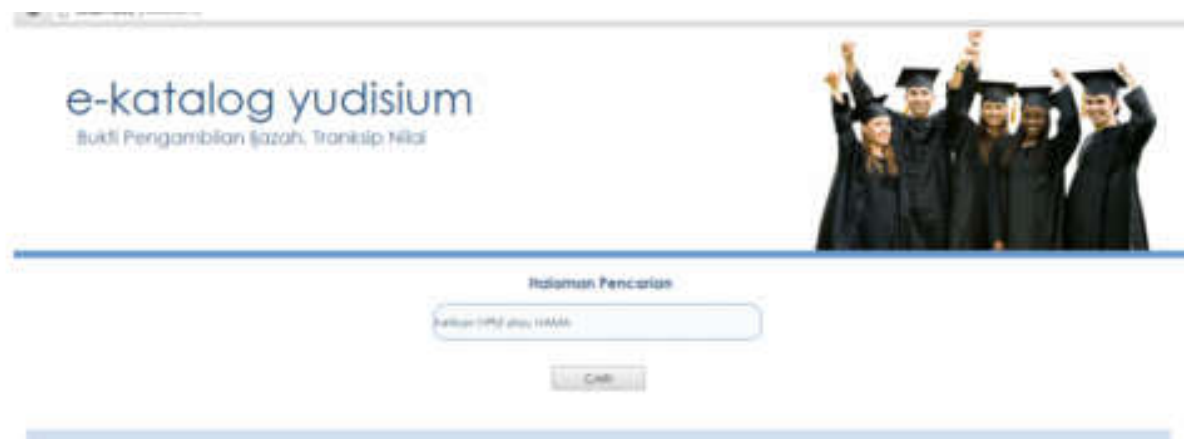

Gambar 5.Interface dan Input Pencarian User

Gambar 5 diatas merupakan interface sekaligus halaman input pencarian untuk user atau mahasiswa, yang mana mahasiswa meginputkan NPM atau nama mahasiswa. Lalu tekan tombol cari. 


\subsubsection{Input Hasil Pencarian}

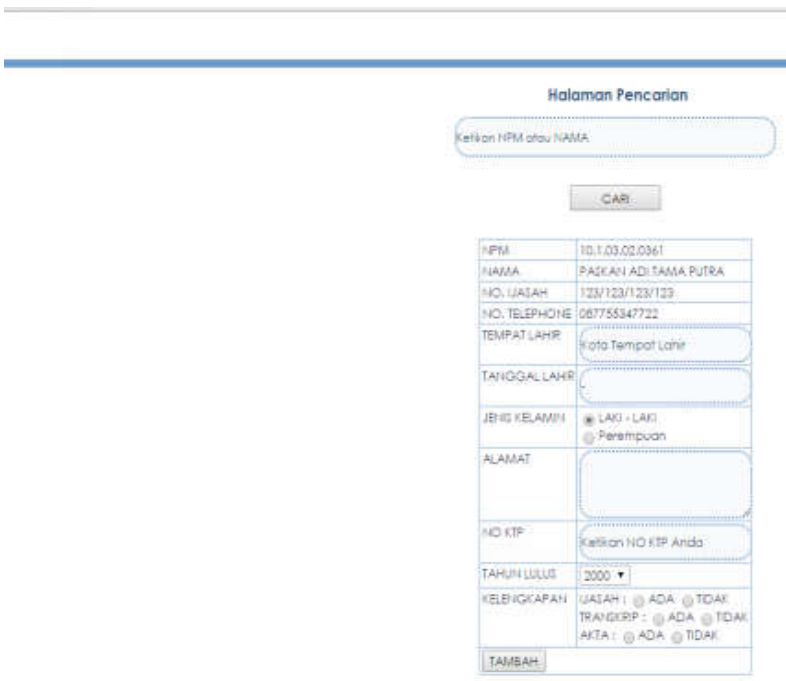

Gambar 6. Hasil Pencarian

Gambar 6. merupakan tampilan dari kelanjutan gambar 6 setelah menekan cari maka tampilan untuk mengisi data mahasiswa yang dicari sesuai pada data ijazah mahasiswa yang diarsipkan.

\subsubsection{Proses Pencarian User}

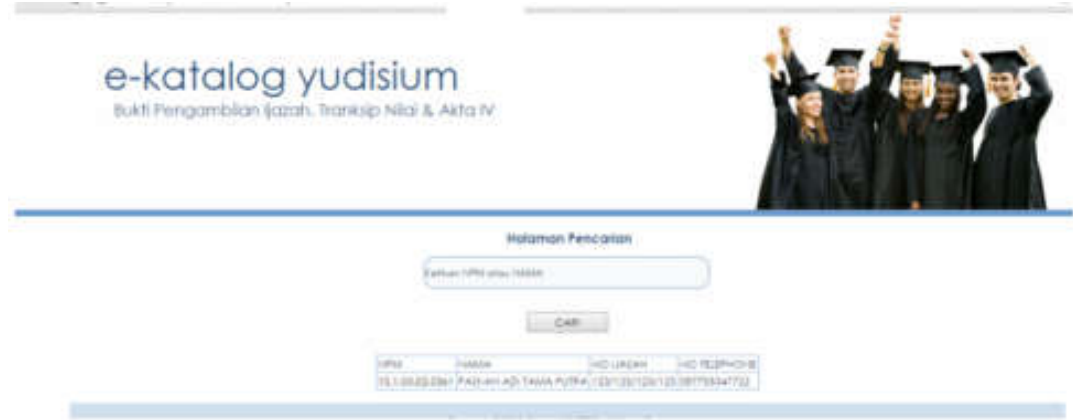

Gambar 7. Proses Tampilan Pencarian

Gambar 7 diatas merupakan form untuk proses menampilkan data ijazah mahasiswa yang dicari.Diform tersebut akan menampilkan npm, nama, no ijasah dan nomer telephone mahasiswa tersebut.

\subsubsection{Penambahan Data Baru}

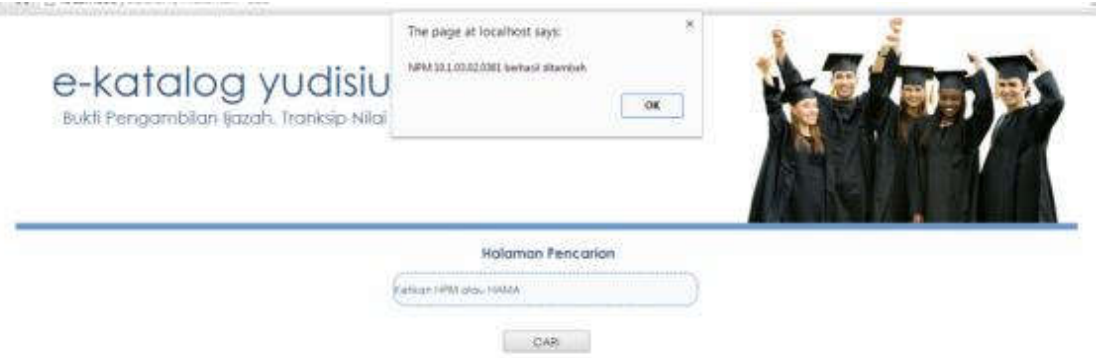

Gambar 8. Penambahan Data Baru

Gambar 8 penambahan data baru merupakan hasil penambahan penyimpanan arsip ijasah untuk data baru ijasah mahasiswa. 


\subsubsection{Login Admin}

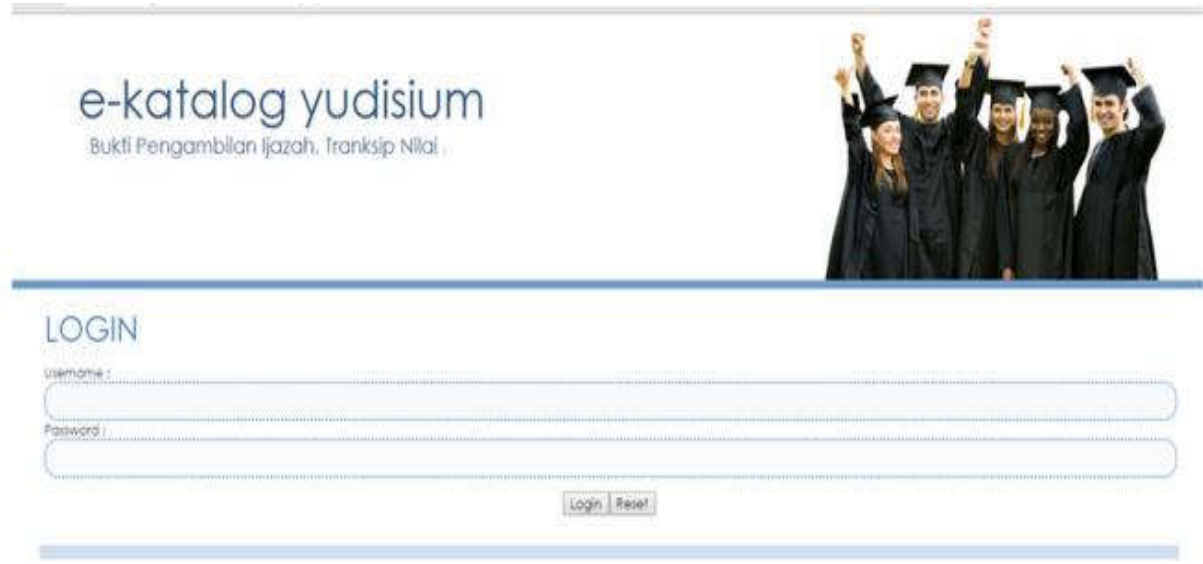

Gambar 9. Form Login Untuk Admin

Gambar 9. merupakan gambar interface dan login untuk admin dimana admin sebelumnya harus login dengan mengisi username dan password.

\subsubsection{Login Gagal}

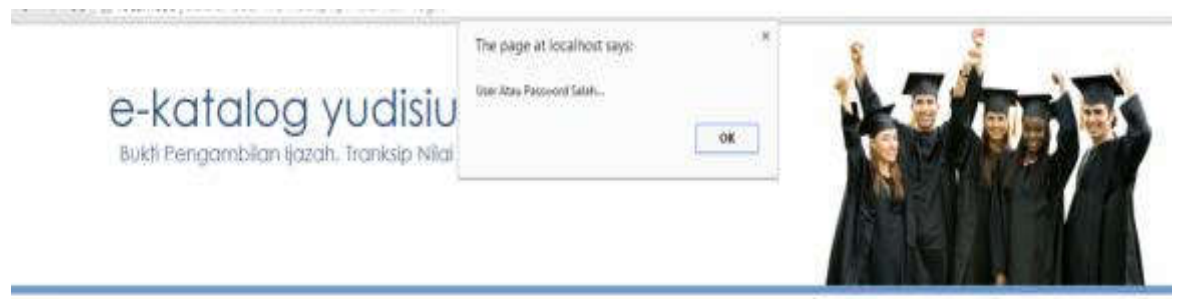

Gambar 10. Form Login Gagal

Gambar 10. merupakan form yang menampilkan kegagalan dalam proses login, jadi apabila admin salah menginputkan user dan passwor maka akan tampil pesan user atau password salah

\subsubsection{Login Berhasil}

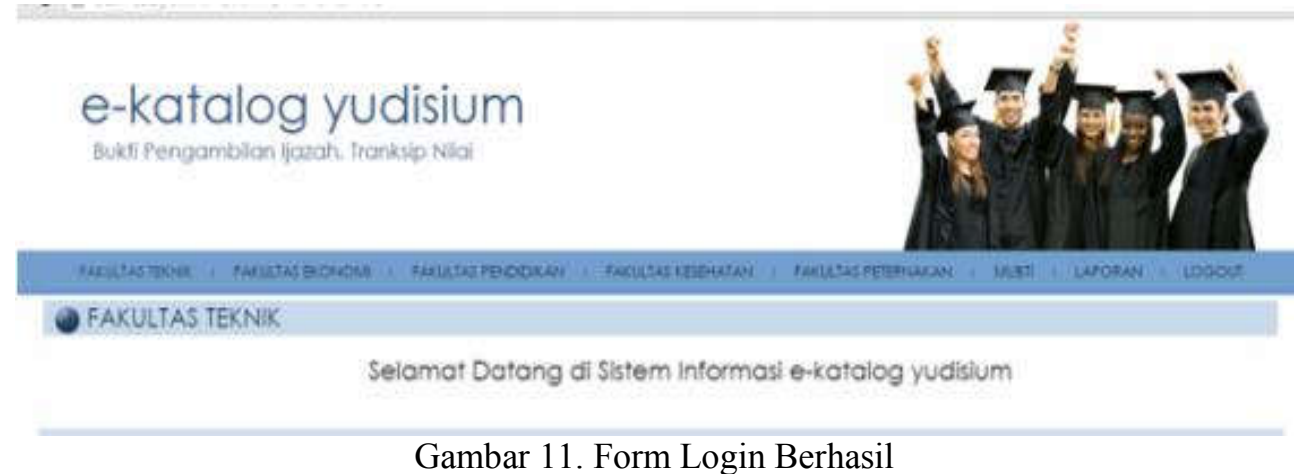

Gambar 11 merupakan form yang menampilkan berhasil dalam proses login, jadi apabila admin benar menginputkan user dan password maka akan tampil selamat datang di Sistem Informasi e-ktalog yudisium 


\subsubsection{Input Data Yudisium}

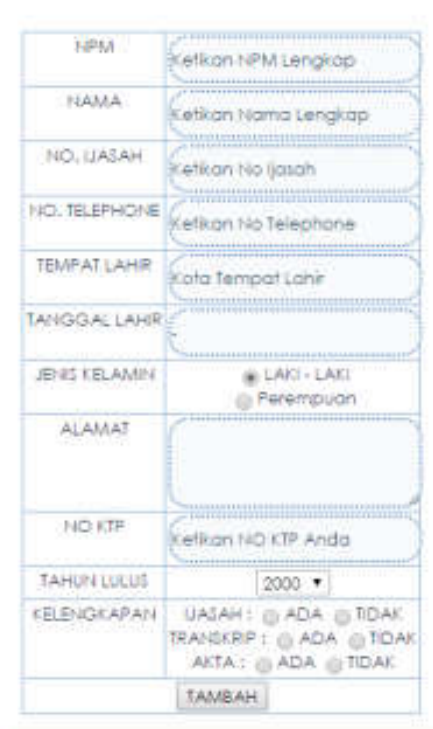

$1+1$ Tambon Dato

Gambar 12. Input Data Yudisium

Setelah login maka proses berikutnya menginputkan data yudisium seperti gambar 12. Yang nantinya akan dimasukkan didaftarkan untuk pembuatan ijasah dan transkrip.

\subsubsection{Pengisian Data Yudisium( Gagal )}

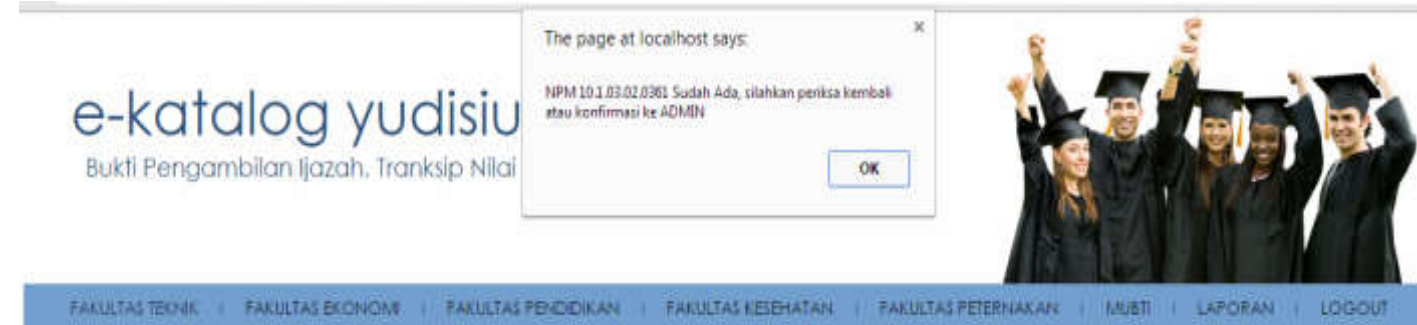

TEKNIK INFORMATIKA

Gambar13. Form Gagal Pengisian Data Yudisium

Gambar 13. merupakan form pengisian data yudisium terjadi kesalahan atau kesamaan dalam pengisian data yudisium, maka akan tampil pesan seperti yang tertera pada gambar 12 .

\subsubsection{Pengisian Data Yudisium ( Berhasil )}

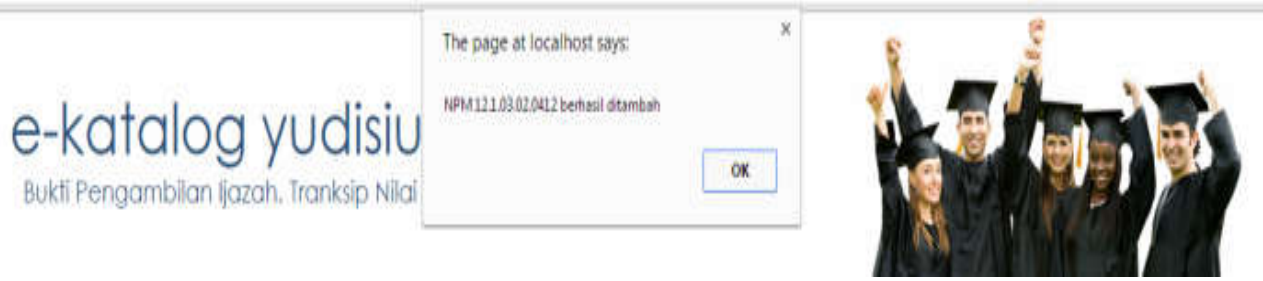

Gambar 14. Form berhasil Pengisian Data Yudisium

Gambar 14 merupakan form pengisian data yudisium yang sudah berhasil dalam pengisian data yudisium, maka akan tampil pesan seperti yang tertera pada gambar 13. 


\subsubsection{Laporan}

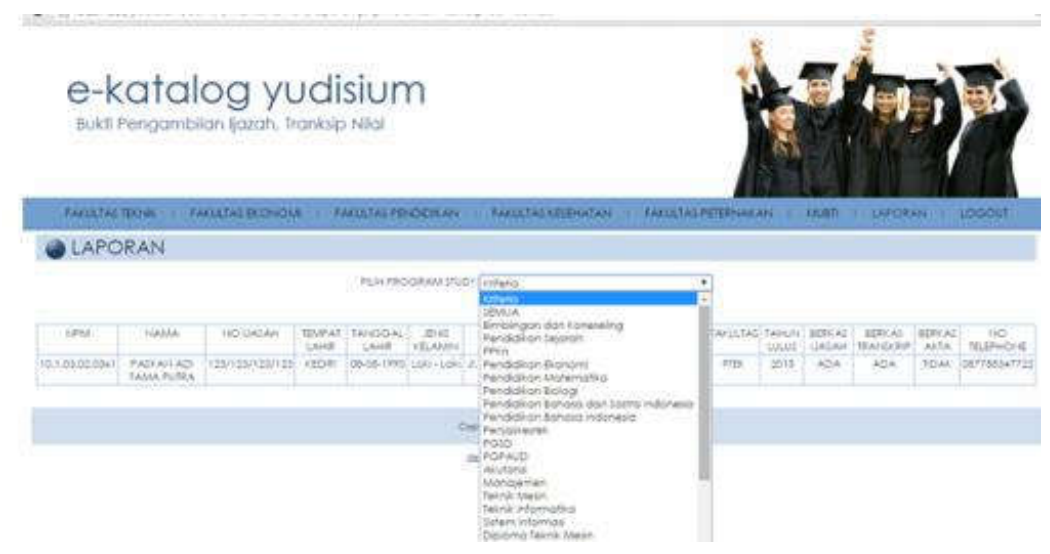

Gambar 15. Form Laporan

Gambar 15 merupakan form untuk pencarian apabila ada mahasiswa yang mengambil ijazah dan transkrip. Dimana nanti user tinggal mencari dan memilih fakultas yang diinginkan setelah itu baru mencari prodi dan NPM atau nama mahasiswa lalu tampil daftar nama yang dicari.

\section{KESIMPULAN}

1. Dengan Aplikasi E-Katalog Yudisium Bukti Pengambilan Ijazah dan Transkrip Nilai dapat membantu para staf BAAK dalam penyimpanan data mahasiswa yang sudah mengambil Ijazah dan Transkrip Nilai.

2. Pengujian sistem mulai dari penekanan tombol login, pengujian penampilan data,pengujian input data dan menampilkan laporan admin dan mahasiswa sudah mengujinya dan program bisa diterima.

\section{DAFTAR PUSTAKA}

Andri Kristanto (2008 : 1 ) Perancangan Sistem Informasi dan Aplikasinya Gava Media, Yogyakarta. Buana, I Komang Setia. 2014. Jago Pemrograman Php. Jakarta: Dunia Komputer.

Nugroho. 2013. Mengenal Xampp Awal. Yogyakarta: Mediakom.

Madcoms Madiun. 2016. Pemrograman Php Dan Mysql Untuk Pemula. Penerbit Andi Yogyakarta.

Arief, M. Rudyanto. 2011. Pemrograman Web Dinamis Menggunakan Php \& Mysql. Yogyakarta : Andi.

Sadeli, Muhammad. 2014. Aplikasi Bisnis Dengan Php Dan Mysql Menggunakan Dreamweaver Cs6. Palembang: Maxikom.

Abdul Kadir (2013). Pengertian MySQL. Tersedia dalam : Buku Pintar Programer Pemula PHP. Yogyakarta. Mediakom.

Ridho Pamungkas[137:2017] Perancangan sistem informasi pembayaran administrasi SMK Negeri 1 Jiwan Jurnal INTENSIF

Dwi Ari Wibowo, Verry Riyanto, Syifa Nur Rakhmah [41:2017] Sistem Informasi Perpustakaan Bebasis Web Pada Smk Negeri 2 Kota Bekasi Jurnal INKOFAR

Indra Budi Trisno dan Wiria Candra[147:2018] Rancang Bangun Aplikasi Pencatatan Stok dan Penjualan UD Pawon Kue Jurnal INTENSIF

Manase Sahat H Simarangkir, Adam Puspabhuanasari[1:2019]. Implementasi Wap (Wireless Application Protocol) Dan Web Untuk Layanan Sistem Informasi Nilai Mahasiswa Teknologi Wireless Application Protocol (WAP ) Jurnal INKOFAR 